\title{
Assessment of phalangeal bone loss in patients with rheumatoid arthritis by quantitative ultrasound
}

\author{
P Röben, R Barkmann, S Ullrich, A Gause, M Heller, C-C Glüer
}

\begin{abstract}
Objective-Periarticular osteopenia is an early radiological sign of rheumatoid arthritis (RA). Quantitative ultrasound (QUS) devices have recently been shown to be useful for assessing osteoporosis. In this study the capability of a transportable and easy to use QUS device to detect skeletal impairment of the finger phalanges in patients with RA was investigated.

Methods-In a cross sectional study 83 women (30 controls, 29 with glucocorticosteroid (GC) treated RA, and 24 with GC treated vasculitis) were examined. QUS measurements were obtained at the metaphyses of the proximal phalanges II-V and directly at the proximal interphalangeal joints II-IV with a DBM Sonic 1200 (IGEA, Italy) QUS device. Amplitude dependent speed of sound (AD-SoS) was evaluated. In 23 of the patients with RA, hand radiographs were evaluated.

Results-Significant differences between patients with RA and the other groups were found for AD-SoS at both measurement sites. Compared with age matched controls, the AD-SoS of patients with RA was lowered by two and three standard deviations at the metaphysis and joint, respectively. Fingers of patients with RA without erosions (Larsen score 0-I) already had significantly decreased QUS values, which deteriorated further with the development of erosions (Larsen II-V). Conclusion-This study indicates that QUS is sensitive to phalangeal periarticular bone loss in RA. QUS is a quick, simple, and inexpensive method free of ionising radiation that appears to be suited to detection of early stages of periarticular bone loss. Its clinical use in the assessment of early RA should be further evaluated in prospective studies. (Ann Rheum Dis 2001;60:670-677)
\end{abstract}

Rheumatologie,

Universitätsklinikum

Lübeck and

Rheumaklinik Bad

Bramstedt GmbH,

Germany

S Ullrich

A Gause

Correspondence to: Professor C-C Glüer, Medizinische Physik, Klinik für Diagnostische

Radiologie,

Universitätsklinikum Kiel, Michaelisstr 9, $24105 \mathrm{Kiel}$, Germany

glueer@rad.uni-kiel.de

Accepted 16 November 2001 occur before manifest erosions are detectable. ${ }^{11} 12$ The process, in which locally increased bone turnover has an important role, ${ }^{13}$ can continue even in the absence of other signs of disease activity. ${ }^{12}{ }^{14}$ Therefore, the need for therapeutic intervention may be missed, because the patient's symptoms and monitoring data suggest the absence of disease activity. Conventional $x$ ray evaluation of the hands and feet is well established as an outcome measure in RA. ${ }^{15}{ }^{16}$ Unfortunately, many $x$ ray scoring techniques depend on the presence and further development of erosions to indicate progression of disease significantly. ${ }^{17}$ Erosions, though, are a sign of advanced disease and indicate substantial, irreversible bone damage. To assess the progression of RA more accurately in the early stages, it seems therefore desirable to be able to quantify the periarticular osteopenia. ${ }^{18}$

Several $x$ ray based techniques have been developed to monitor bone loss of the hand. ${ }^{19-22}$ Each of them has its individual advantages and disadvantages of sensitivity, precision, simplicity, cost effectiveness, and availability. All of them expose the patient to ionising radiation, even though the dose is extremely low in dual energy $x$ ray absorptiometry (DXA). The use of any $x$ ray device requires strict adherence to radiation safety regulations and special training of the personnel. Computerised analysis of digitised plain hand radiographs (also displaying an aluminium wedge), known as radiographic absorptiometry, ${ }^{22}$ lacks simplicity. In a simplified version of radiographic absorptiometry only the middle phalanx of the third finger is evaluated, ${ }^{19}$ which may impair the sensitivity in patients whose middle finger is not affected. Therefore these methods have been superseded by the more precise DXA technique. However, availability limits the use of DXA of the hand. Radiogrammetry is a traditional method for the measurement of periarticular bone loss, ${ }^{23-25}$ but it is less precise than DXA and therefore of limited use for monitoring purposes. ${ }^{26}{ }^{27}$ First studies indicate improved precision for a new method (digital radiogrammetry) combining computerised radiogrammetric and texture analysis of the hand. However, no studies on patients with RA have yet been carried out. ${ }^{28}$

This article considers whether QUS devices can detect changes in the periarticular and metaphysial bone of patients with RA. For this purpose, we used a device (DBM Sonic 1200, IGEA, Italy) which is specially designed for 
Table 1 Characteristics of the groups investigated: age, cumulative duration of glucocorticoid $(G C)$ treatment and disease duration

\begin{tabular}{lllll}
\hline Group & No & $\begin{array}{l}\text { Age } \\
\text { Mean (SD) [range] }\end{array}$ & $\begin{array}{l}\text { GC treatment (years) } \\
\text { Mean (range) }\end{array}$ & $\begin{array}{l}\text { Presence of disease } \\
\text { (years) } \\
\text { Mean (range) }\end{array}$ \\
\hline RA & 29 & $53.6(11.7)[20-70]$ & $3.5(0-27)$ & $10.7(0.5-36)$ \\
Vasculitis & 24 & $49.0(15.8)[19-68]$ & $1.7(0.5-6)$ & $3.7(0.5-20)$ \\
Control & 30 & $41.3(13.4)[22-67]$ & - & - \\
\hline
\end{tabular}

QUS measurements near the proximal interphalangeal (PIP) joints of fingers. Several studies have shown that the QUS results obtained with the DBM Sonic correlate with bone density of the lumbar spine and the hip and that patients with and without vertebral or hip fractures might be identified. ${ }^{29-32}$ In one prospective study it was reported that the risk of osteoporotic fracture could be predicted. ${ }^{33}$ In RA these associations may be even stronger because peripheral periarticular loss of bone may progress faster than osteoporosis of the axial skeleton. Previous studies have shown that findings with the DBM Sonic correlate well with bone density in the measured region, ${ }^{34}$ metacarpal index, ${ }^{32}$ and cortical cross sectional area. ${ }^{36}$ However, only a small number of published studies have investigated patients with RA using this device..$^{35} 38$ They showed reduced ultrasound velocity for patients with RA in comparison with patients with general osteopenia or healthy subjects. We investigated whether QUS may allow measurement of bone loss in patients with RA and how the sensitivity for assessing early changes compares with Larsen scoring using conventional hand radiography. In addition, we wanted to explore whether the skeletal changes measured by QUS are primarily associated with generalised bone loss due to GC treatment or with the periarticular bone loss due to immobilisation secondary to pain, inflammation, and destruction. Therefore, in addition to subjects with RA and a healthy control group, we also recruited a group of patients with vasculitis who had received GC treatment at relevant dose levels but who did not have the finger joint problems associated with RA.

\section{Methods}

A group of 29 female patients with RA was compared with a control group of 30 healthy women and a group of 24 female patients with different types of vasculitis. Patients (RA and vasculitis group) between the ages of 20 and 70 years and a minimum duration of disease of six months were recruited from a rheumatology ward. For the RA group, diagnosis had been established by a rheumatologist of the Rheumaklinik Bad Bramstedt according to the diagnostic criteria of the American College of Rheumatology. Six of the 29 patients were seronegative. Patients were admitted to hospital either for check up procedures and treatment modification or because of acute exacerbation of their illness. Patients with swollen or acutely inflamed and tender PIP joints were excluded from the study. The vasculitis group consisted of patients with polyarteritis nodosa (classic, microscopic, or overlap), Wegener's vasculitis, Churg-Strauss disease, or Behçet's syndrome. Patients of the vasculitis group had to have been treated with GC for a cumulative duration of at least six months. No such exclusion criterion was applied to the RA group, but only three patients with RA had never been treated with GC and the mean treatment duration was even longer than for the patients with vasculitis (table 1). Owing to the setting of our study, it was not possible to obtain highly reliable information about the cumulative (prednisolone equivalent) dose of GC used throughout a patient's life. However, all the patients in the vasculitis group and 26 of 29 patients with RA had received GC of more than $7.5 \mathrm{mg}$ prednisolone equivalent for a considerable amount of time (table 1). The control group was selected randomly from women waiting in a dentist's office who did not have a known history of skeletal impairment like osteoporosis or

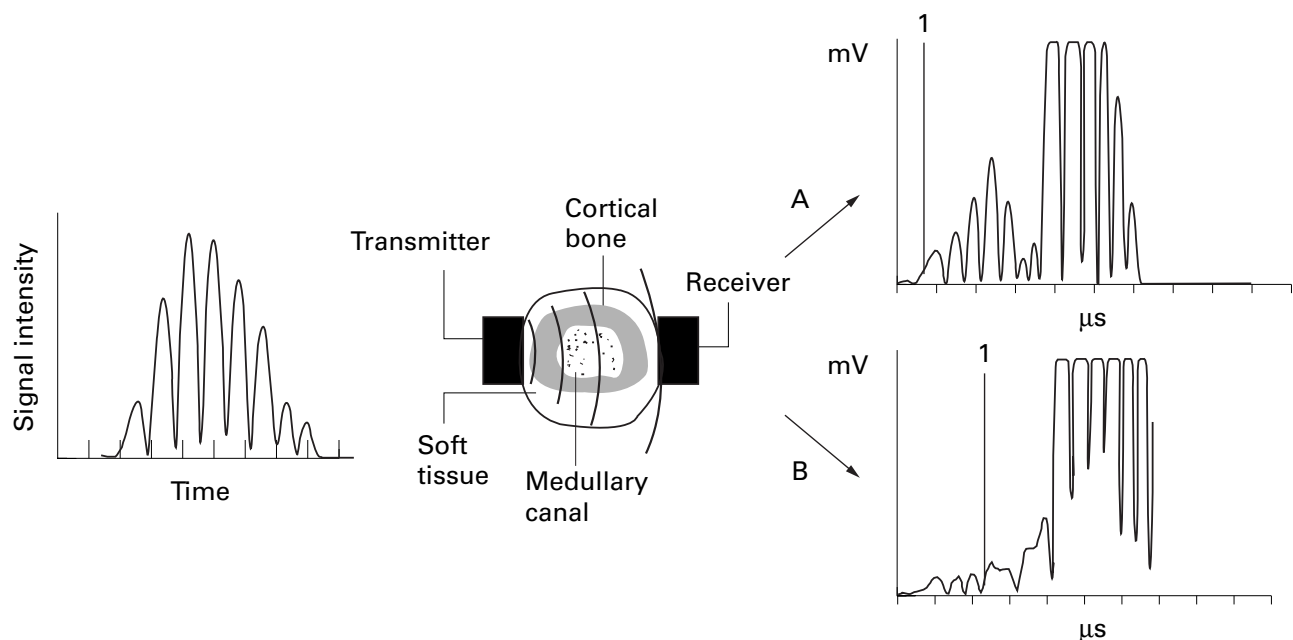

Figure 1 Principle of quantitative ultrasound measurement using the DBM Sonic 1200. The generated ultrasound signal (left) is transmitted through the finger (middle). The received signal (right) is displayed and evaluated: $A=$ metaphysis of the proximal phalanx II of a healthy woman, 47 years old with $A D-S o S=2082 \mathrm{~m} / \mathrm{s} ; B=$ measurement at the same site of a 50 year old woman who had had rheumatoid arthritis for 11 years with AD-SoS=1728 m/s. Marker 1: At this point in time the signal intensity reached the trigger level to measure AD-SoS. 


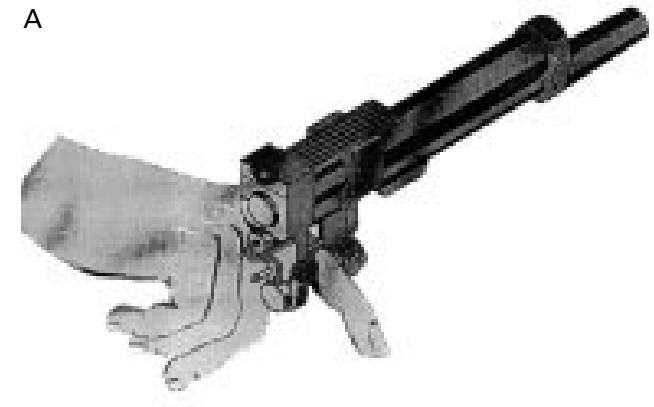

B

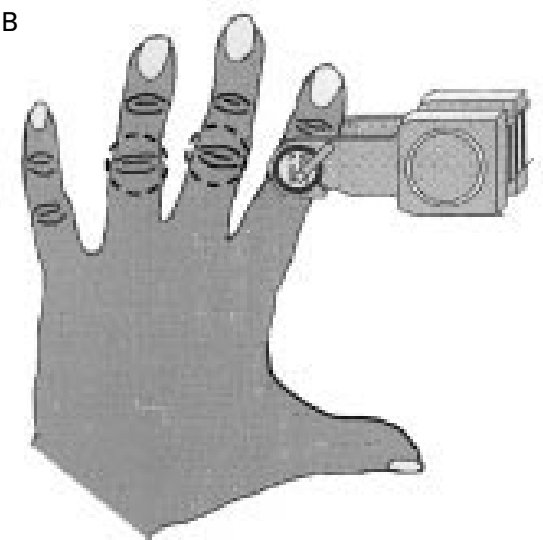

Figure 2 (A) Measurement at the metaphysis of the proximal phalanx II (standard mode). (B) Dorsovolar measurement at the proximal interphalangeal joint. The probes are positioned by palpation of the joint gap.

arthritis. Their age range was similar to that of the other groups, but their lower average age required statistical adjustment for age effects in our analyses.

The ultrasound device used in our study was a DBM Sonic 1200 (IGEA, Carpi, Italy). ${ }^{39}$ Two probes, transmitter and receiver, are positioned opposite to each other by a high precision caliper, with the finger in between and coupling achieved by ultrasound gel. The DBM Sonic transmits an ultrasound wave at frequency of $1.2 \mathrm{MHz}$. The standard parameter of ultrasound velocity as measured by the DBM Sonic 1200 is "amplitude dependent

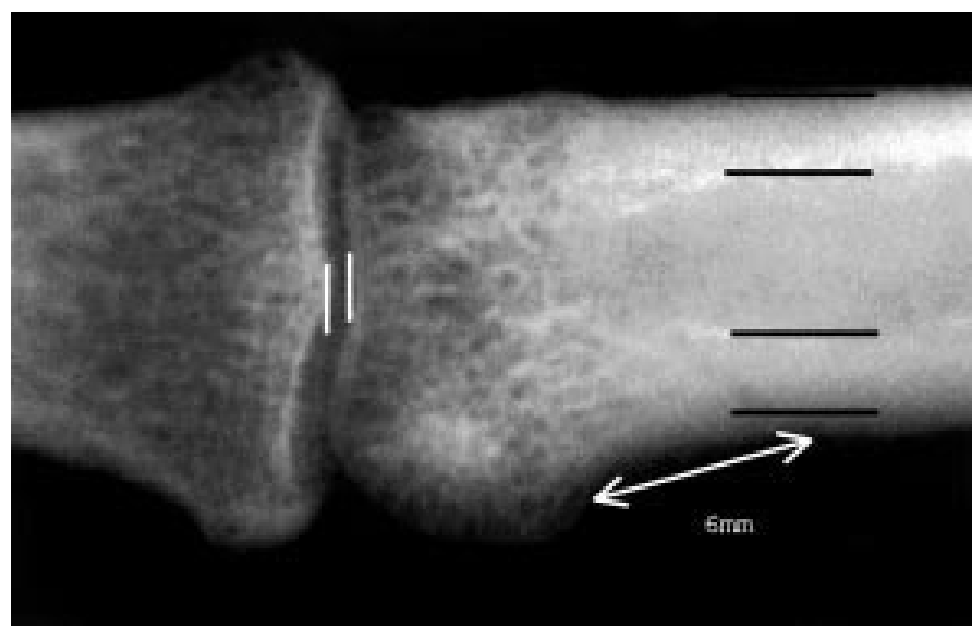

Figure 3 Hand $x$ ray. This example of the evaluation of proximal interphalangeal joints depicts how cortical index and joint gap narrowing were determined. Cortical thickness was measured $6 \mathrm{~mm}$ proximal to the widening of the epiphysial head because this is the site where the ultrasound beam penetrates the finger in the standard measurement mode. speed of sound" (AD-SoS). It is defined as the distance between the transducers divided by the time of flight, which is the period between signal generation at the transmitting probe and an evoked amplitude of approximately $2 \mathrm{mV}$ at the receiving probe. As the name implies, $\mathrm{AD}-\mathrm{SoS}$ depends both on the velocity and the amplitude of the signal received. Figure 1 shows examples of ultrasound waves received at the metaphysis.

\section{MEASUREMENT SITES}

A standard measurement at the metaphysis of the proximal phalanges II-V in the radioulnar direction was performed twice at the right hand and once at the left hand ("metaphysis" measurement, fig 2A). Additionally, we investigated $\mathrm{AD}-\mathrm{SoS}$ directly at the PIP joint. Here, each (left and right) PIP joint of the phalanges II, III, and IV was investigated twice in the dorsovolar direction, with the probes centred on the joint gap ("joint" measurement, fig $2 \mathrm{~B}$ ). This is a new measurement mode developed by our group.

To assess the reproducibility of the technique, the short time precision of $\mathrm{AD}-\mathrm{SoS}$ was calculated from the duplicate hand measurements using root mean square averages. ${ }^{40} \mathrm{We}$ calculated the precision of the standard hand measurement (mean of four finger measurements: index, middle, ring, small) at the metaphysial site and also for the joint measurement procedure (mean of three finger measurements: index, middle, ring).

Hand radiographs of 23 patients with RA, which had been taken within the past six months before the ultrasound investigation (median period between radiography and QUS measurement was 21 days), were digitised and evaluated. Larsen stages for each PIP joint, as well as joint gap narrowing and the cortical index (cortical thickness in relation to the width of the metaphysis) were determined from these films (fig 3). The Larsen score of a single finger was compared with the QUS value of the corresponding fingers (single finger analysis). The mean of the cortical index of the phalanges II-IV of both hands was compared with the mean AD-SoS of the corresponding phalanges.

\section{STATISTICAL ANALYSIS}

To account for age related effects we compared the groups by calculating $\mathrm{Z}$ scores (defined as the number of standard deviations decrease from age matched healthy reference groups). For $\mathrm{AD}-\mathrm{SoS}_{\text {metaphysis }}$ the $\mathrm{Z}$ score could be calculated from the reference database provided by the manufacturer (IGEA, Carpi, Italy). For $\mathrm{AD}-\mathrm{SoS}$ at the joint, reference data are not yet available. To estimate the $\mathrm{Z}$ score for this measurement we used the data obtained from the control group. A cubic regression analysis was applied to account for a relatively stable premenopausal period, an accelerated bone loss in early postmenopause, and a reduced bone loss at older ages. From this curve $\left(\mathrm{R}^{2}=0.61\right)$ the "normal" status at each age could be calculated and the standard error of the estimate provided a figure for the variance 
Table 2 Mean (SD) values of quantiative ultrasound parameters for the three subject groups

\begin{tabular}{lllll}
\hline Site & Parameter & Controls & Vasculitis & $R A$ \\
\hline Metaphysis & AD-SoS (m/s) & $2077(79.7)$ & $2021(78.7)$ & $1875(138.9)^{\star}$ \\
& Z score & $-0.19(0.67)$ & $-0.37(1.01)$ & $-2.08(1.25) \dagger$ \\
Joint & AD-SoS (m/s) & $1921(27.1)$ & $1914(25.8)$ & $1842(59.7)^{\star}$ \\
& Z score & $0.01(0.86)$ & $0.39(1.56)$ & $-3.01(2.71) \dagger$ \\
\hline
\end{tabular}

${ }^{\star} \mathrm{p}<0.0001, \mathrm{tp}<0.001$, significance levels $v$ controls and $v$ vasculitis group.

Table 3 Quantitative ultrasound results displayed for two subgroups of patients with less and more than five years' disease duration

\begin{tabular}{lllll}
\hline Parameter & Site & Controls & $\begin{array}{l}\text { Early } R A(<5 \text { years' } \\
\text { disease duration })(n=12)\end{array}$ & $\begin{array}{l}\text { Advanced } R A(>5 \text { years } \\
\text { disease duration })(n=17)\end{array}$ \\
\hline AD-SoS & & & & \\
Z score & Metaphysis & $-0.19(0.67)$ & $-1.66(1.36)$ & $-2.37(1.12)$ \\
$Z_{\text {score }}$ est & Joint & $+0.01(0.86)$ & $-2.42(1.51)$ & $-3.55(3.27)$ \\
\hline
\end{tabular}

of a "normal" population. Estimated Z scores $\left(Z\right.$ score $\left._{\text {est }}\right)$ could then be calculated for each subject. The $\mathrm{Z}$ score and $\mathrm{Z}$ score $_{\text {est }}$ of the three groups were then compared using the TukeyKramer HSD test. To investigate the change in $\mathrm{AD}-\mathrm{SoS}$ during early disease, we also divided the RA group into two subgroups - those with disease duration of less than five years and more than five years. Correlations between $\mathrm{AD}-\mathrm{SoS}$ and morphological findings on $x$ ray films were assessed by calculating Pearson correlation coefficients. Nominal logistic regression models were applied to investigate the ability of the ultrasound parameters to discriminate between patients with $\mathrm{RA}$ and healthy controls. These and all other statistical analyses were carried out using the JMP software package (SAS Institute Inc, Cary, NC, USA).

\section{Results}

The precision errors were $0.5-0.8 \%$ for $\mathrm{AD}-\mathrm{SoS}_{\text {metaphysis }}$ and $0.3-0.4 \%$ for $\mathrm{AD}-\mathrm{SoS}_{\text {joint }}$ in the three subject groups. No significant differences in precision were found between the groups.

Table 2 lists the results of the QUS parameters for the three subject groups expressed in $\mathrm{m} / \mathrm{s}$ and as $\mathrm{Z}$ scores to adjust for age related effects. AD-SoS of the control group was consistent with the reference database of the manufacturer as the mean $\mathrm{Z}$ score is approximately zero.

In patients with $\mathrm{RA}, \mathrm{AD}-\mathrm{SoS}$ was significantly reduced: at the metaphysis as well as at the joint $\mathrm{AD}-\mathrm{SoS}$ was significantly lower in the RA group than in the other two groups $(\mathrm{p}<0.0001 v$ controls and $v$ vasculitis group). No significant difference was found between the vasculitis and the control group. After adjusting for age related effects by calculating $\mathrm{Z}$ scores, the difference was still highly significant

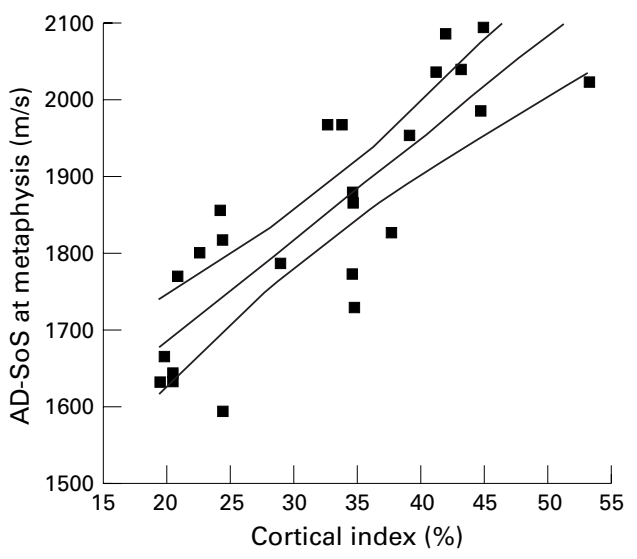

Figure 4 Correlation between AD-SoS at metaphysis and cortical index. $\left(R^{2}=0.71, p<0.0001\right)$. Displayed are the mean values averaged across six fingers (left and right phalanx $I I-I V)$ for 23 patients with $R A$, the linear regression line, and the $95 \%$ confidence intervals of the regression line.

( $\mathrm{p}<0.001 v$ controls and $v$ vasculitis group). For predicting the presence of RA by age adjusted $\mathrm{AD}-\mathrm{SoS}_{\text {joint }}$ or $\mathrm{AD}-\mathrm{SoS}_{\text {metaphysis }}(\mathrm{Z}$ scores), or both, using nominal logistic regression models, $\mathrm{AD}-\mathrm{SoS}_{\text {ioint }}$ was as powerful as $\mathrm{AD}-\mathrm{SoS}_{\text {metaphysis }}$ in discriminating between patients with RA and healthy subjects $\left(\mathrm{R}^{2}=0.48 v\right.$ $0.53)$. Both variables contributed independently to the model and for the combined model $\mathrm{R}^{2}$ increased to 0.65 .

Table 3 shows the results for the two subgroups of RA with early and advanced disease duration. Subjects with a disease duration of less than five years of RA (mean 40 months) already had significantly reduced QUS values ( $\mathrm{Z}$ score of -1.66 for $\mathrm{AD}-\mathrm{SoS}_{\text {metaphysis, }}$ $\mathrm{p}<0.0001)$.

$X$ RAY EVALUATION

No relation was found between joint gap narrowing and any of the ultrasound findings. However, we found a strong correlation between the cortical index (combined width of the cortical bone divided by the width of the phalanx) and AD-SoS. Figure 4 shows the correlation between the cortical index and ADSoS $_{\text {metaphysis }}\left(R^{2}=0.71, p<0.0001\right)$. Significant correlations with cortical index were also found for $\mathrm{AD}-\mathrm{SoS}_{\text {joint }}\left(\mathrm{R}^{2}=0.53, \mathrm{p}<0.0001\right)$. AD$\mathrm{SoS}_{\text {joint }}$ correlated with cortical index, even though the index was obtained from the metaphysis.

Table 4 shows a comparison of ultrasound velocity in fingers with and without erosions (Larsen 0-I $v$ Larsen II-V, single finger analysis). It shows that most of the difference between the RA group and the control group is

Table 4 Single finger analysis. Comparison of ultrasound values in fingers of healthy controls, non-eroded and eroded fingers of patients with rheumatoid arthritis (RA). Analysis for subgroup of patients with $R A$ for whom radiographs were available and restricted to phalanges of index, middle, and ring fingers. Thus values are not comparable with those of table 2

\begin{tabular}{|c|c|c|c|c|c|}
\hline Parameter & Site & $\begin{array}{l}\text { Controls } \\
\text { ( } n=180 \text { fingers) }\end{array}$ & $\begin{array}{l}\text { No erosions } \\
\text { ( } n=77 \text { fingers) }\end{array}$ & $\begin{array}{l}\text { Erosions present } \\
\text { ( } n=61 \text { fingers) }\end{array}$ & $\begin{array}{l}\text { After age } \\
\text { adjustment }\end{array}$ \\
\hline $\mathrm{AD}-\mathrm{SoS}(\mathrm{m} / \mathrm{s})$ & $\begin{array}{l}\text { Metaphysis } \\
\text { Joint }\end{array}$ & $\begin{array}{l}2094(97) \\
1921(31)\end{array}$ & $\begin{array}{l}1881(174)^{\star} \\
1859(39)^{\star}\end{array}$ & $\begin{array}{l}1767(138) \dagger \ddagger \\
1804(68) \dagger \ddagger\end{array}$ & $\begin{array}{l}\star \star \\
\star \\
\star\end{array}$ \\
\hline
\end{tabular}

Significance levels are indicated as follows: ${ }^{\star} \mathrm{p}<0.001$, no erosions $v$ controls; $\uparrow \mathrm{p}<0.0001$, erosions $v$ controls; $\neq \mathrm{p}<0.001$, erosions $v$ no erosions . Last column shows significance levels in the same fashion after adjustment for age (Tukey- Kramer HSD). 

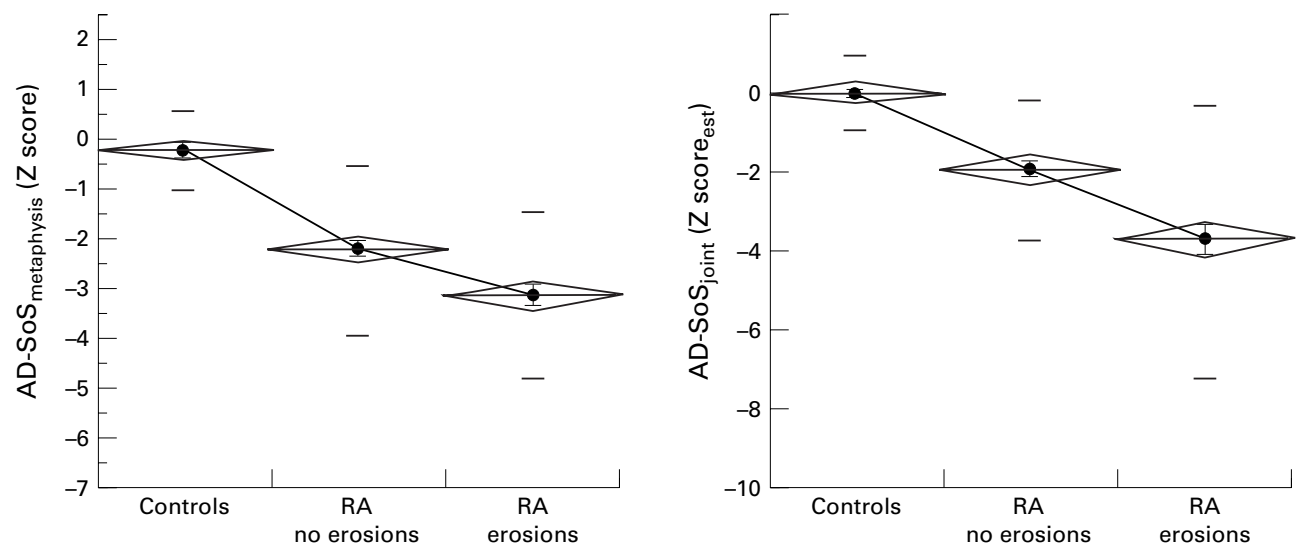

Figure 5 Age adjusted and finger specific QUS Z scores for fingers with and without erosions compared with healthy controls (based on subjects for whom radiographs were available). Ultrasound velocity of $R A$ fingers with erosions is significantly decreased compared with those without erosions. This result is found at both measurement sites. The diamonds represent the $95 \%$ confidence interval (height of the diamond) of the mean (horizontal centre line).

already evident in fingers without erosions. With further progression, the ultrasound parameters deteriorate increasingly. Still, after adjustment for age and using finger-specific reference data, AD-SoS showed a highly significant difference between fingers with and without erosions at both sites. Differences were slightly more significant when measured at the joint. Figure 5 depicts these results as fingerspecific Z scores.

\section{Discussion}

The two QUS approaches tested in this study both showed significant differences between patients with RA and the control groups. A finger-specific analysis demonstrated a better sensitivity to RA induced bone loss than detection of erosions by radiography. QUS of the phalanges thus appears to represent a sensitive tool for assessing periarticular bone loss in RA.

A significant loss in $\mathrm{AD}-\mathrm{SoS}$, especially in the early stages of RA, has been documented by our study. The subgroup of patients with less than five years of disease duration presented with a $\mathrm{Z}$ score already of about -1.6 . The single finger analysis showed that QUS values decline even before irreversible erosions are detectable. The same finding has been reported by Alenfeld et $a l^{\beta 8}$ and is in agreement with several reports of a fast periarticular bone loss, particularly in the early stages of RA. ${ }^{121}$ Thus QUS may be particularly well suited to assess early skeletal changes in RA.

In RA, bone loss occurs in the axial skeleton as well as in peripheral bones. Especially in the early stages, peripheral bone loss is more prominent than axial osteopenia. ${ }^{41}$ This characteristic makes RA a very suitable disease for investigation by QUS, which has not yet been developed to obtain direct measurements at the spine or femur. Broadband ultrasound attenuation (BUA) and ultrasound velocity of the calcaneus have previously been reported to be reduced in patients with $\mathrm{RA}$ in comparison with controls. ${ }^{10}$ As mentioned earlier, other studies have found a reduced AD-SoS at the metaphysis of the proximal phalanges in patients with up to five years of RA, whereas spine bone mineral density (BMD) was higher for patients with RA than in primary osteopenia. ${ }^{35}$ A marked peripheral bone loss combined with a normal or moderately reduced spine BMD was observed by Devlin et al in early RA. ${ }^{41}$

The few small studies on phalangeal QUS in RA have all shown a significant reduction of $\mathrm{AD}-\mathrm{SoS}_{\text {metaphysis }}$ in comparison with healthy controls or even osteopenic patients. ${ }^{35}{ }^{37}$ Values for $\mathrm{AD}-\mathrm{SoS}_{\text {metaphysis }}$ of our subgroup with early RA are comparable with those reported in a similar group, ${ }^{38}$ if we consider that Alenfeld et al excluded patients with Larsen stage $>2$ from their study. Njeh et al showed that these results correlate well with BMD measured by DXA in this region of interest (metaphysis of the proximal phalanges). ${ }^{35}$ That is in agreement with our result of the single finger analysis, which showed that $71 \%$ of the variation in $\mathrm{AD}$ $\mathrm{SoS}_{\text {metaphysis }}$ could be explained by the relative thickness of the cortex at this site (fig 4). Similar findings have been reported previously by our group and others. ${ }^{32}{ }^{42}$ Thus QUS parameters will be influenced mainly by bone density, but they are also reported to be influenced by other skeletal properties, such as bone geometry, bone structure, and quality. ${ }^{23} 363943-45$ In this respect, QUS should not be viewed as a simple substitute for $x$ ray based densitometry techniques. Especially in RA, where the changes in bone structure are complex, the data provided by QUS may yield a more comprehensive representation of skeletal impairment.

One innovation of this study is the measurement with QUS directly at the joints and their adjacent bone. We found at the PIP joints that $\mathrm{AD}-\mathrm{SoS}_{\text {joint }}$ is also significantly reduced in patients with RA. This approach is the consequence of the idea of measuring close to the site where the disease process is located. Similar approaches have been tested for DXA, where regions of interest were evaluated near the PIP joints ${ }^{35}$ or near the metacarpophalangeal joints. ${ }^{38}$ They found a marked bone loss compared with whole hand measurements but faced at the same time problems concerning precision and accuracy as well as extensive 
operator training in determining the regions of interest.

At the joint measurement site a large component of trabecular bone is present which probably affects ultrasound transmission. The reduction of $\mathrm{AD}-\mathrm{SoS}_{\text {joint }}$ in $\mathrm{RA}$ is significant, can be precisely measured, and yields additional independent information from AD$\mathrm{SoS}_{\text {metaphysis }}$, as is shown here by regression models. This is expected because the standard measurement site allows assessment of velocity changes caused by alterations of mostly cortical rather than trabecular bone. More research is needed to evaluate the significance of the joint measurement site. It may show that the DBM Sonic is a useful tool for investigating separately cortical (metaphysis) and trabecular (joint) bone status by QUS.

The short term precision errors seen in our study $(0.5-0.8 \%$ in all groups) for a standard hand measurement of $\mathrm{AD}-\mathrm{SoS}_{\text {metaphysis }}$ are in agreement with data previously reported, ${ }^{31} 3347$ indicating that RA induced joint destruction does not severely affect the reproducibility of the measurement. The measurement procedure is optimised for measurements at the metaphysis. Nevertheless, precision errors for $\mathrm{AD}-\mathrm{SoS}_{\text {joint }}$ were found to be even lower $(0.3-0.4 \%)$. Variation between patients, on the other hand, was remarkably lower for $\mathrm{AD}$ $\mathrm{SoS}_{\text {ioint }}$ so that diagnostic sensitivity-that is, the change in RA in relation to the precision error of the method, is not better than $\mathrm{AD}-\mathrm{SoS}_{\text {metaphysis. }}$ AD-SoS is known to be affected by several error sources ${ }^{3643}$ and the impact of soft tissue thickness may be of particular concern in patients with RA. However, patients with swollen joints were not included in the study. Moreover, after correction for age, there was no significant correlation between AD-SoS and finger thickness (which is given automatically by the device) at any site and therefore increased finger thickness in patients with RA cannot have caused the decreases in AD-SoS values.

The ability to monitor longitudinal changes - that is, longitudinal sensitivity, depends on the ratio of precision error and response rate. ${ }^{48}$ For $\mathrm{AD}-\mathrm{SoS}_{\text {metaphysis }}$ response rates per year were approximately twofold higher than the precision error. This indicates that the low precision errors make QUS potentially suitable for monitoring patients, particularly in the early stages of RA. How phalangeal QUS performs compared with DXA of the hand in this respect, will need to be determined by large longitudinal studies. However, our results combined with those previously reported are encouraging and indicate that phalangeal QUS may not be inferior to DXA of the hand. On the other hand, QUS has numerous advantages over DXA, such as costs, size and transportability of the device, and no complications with regulations for the use of $x$ rays, for example. Although our limited, cross sectional investigation may not allow an accurate calculation, we tried to estimate the annual loss, expressed as ultrasound velocity, during the first years of RA. For patients with $0.5-5$ years' disease duration (mean 3.37 years, $\mathrm{n}=12$ ) the annual loss in $\mathrm{AD}-\mathrm{SoS}_{\text {metaphysis }}$ that exceeded the normal age related loss was 39.5 $\mathrm{m} / \mathrm{s}(95 \%$ confidence interval 19 to $60 \mathrm{~m} / \mathrm{s})$. This is likely to be an overestimation, because the true onset of RA will have occurred before its first diagnosis. In this respect, we think that a somewhat lower mean annual loss of $\mathrm{AD}-\mathrm{SoS}_{\text {metaphysis }}$ can be expected, probably also depending on the success of treatment. ADSo $S_{\text {metaphysis }}$ has a longitudinal sensitivity for the detection of periarticular bone loss that is similar to DXA of the hand. Reported precision errors for bone mineral content and BMD range from $1.5 \%$ to $2.3 \%$ and $0.6 \%$ to $1.3 \%$, respectively. ${ }^{20}{ }^{21}{ }^{41}$ For patients with early RA, Deodhar et $a l^{49}$ found an annual bone loss (bone mineral content) of $3.25 \%$ in male and $1.46 \%$ in female patients in a longitudinal study, again approximately twofold higher than the precision errors. These estimations must be interpreted with caution because there are as yet no longitudinal studies for phalangeal QUS in RA, and a direct comparison with hand DXA is required. Still, the data indicate the potential of the new QUS approach.

Bone loss in RA may be due to immobilisation secondary to pain, inflammation, and destruction but it may also be caused by long term GC treatment. To differentiate between these effects we also assessed a group of patients with vasculitis. Surprisingly, we found no significant differences in QUS values between the vasculitis and control groups, despite the substantial GC dose. Kalla et al investigated metacarpal bone density of patients with systemic lupus erythematosus and RA as well as controls and found a markedly reduced bone density for patients with RA. ${ }^{50}$ For patients with systemic lupus erythematosus who where receiving high dose GC treatment, metacarpal bone density was reduced only mildly and was significantly higher than in RA. This is consistent with our QUS findings. Several authors have stated that low dose GC treatment in RA leads to bone loss of the axial rather than the peripheral skeleton. ${ }^{51-53}$ Whether GC mainly influences trabecular bone, and to a lesser extent cortical bone, remains controversial. ${ }^{545}$ One should also consider that the positive influence of cortisone on the course of disease may exceed its negative effects on bone metabolism. ${ }^{5156}$ Our findings of little peripheral bone loss for GC treated vasculitis together with substantial trabecular and cortical bone loss in patients with RA treated with GC, suggest that phalangeal QUS measurements are particularly suited to the study of bone destruction induced by immobilisation or local inflammation rather than that induced by the detrimental effect of GC treatment. Of course, this must be interpreted with caution, because the limitations of our study design preclude further conclusions. Owing to the retrospective design of our study, no reliable investigations about the (cumulative) dose of prednisolone equivalents could be made. Also, BMD measurements were not included in this study, and therefore no information about possible bone loss in the group with vasculitis was available. However, 
owing to the small effect or lack of effect of GC treatment in the group with vasculitis it is most unlikely that the decrease of QUS results in the RA group is caused by GC treatment. However, longitudinal controlled studies would be required to confirm this observation.

Our study has some limitations. The number of subjects is relatively small. However, the control group had $\mathrm{AD}-\mathrm{SoS}_{\text {metaphysis }}$ results similar to the reference data provided by the manufacturer. This shows that no systemic error or bias occurred, which would have compromised the results for the other two groups. New normative reference data have recently been published for $\mathrm{AD}-\mathrm{SoS}_{\text {metaphysis }}{ }^{46}$ No substantial difference between these data and the reference database of the manufacturer has been found, at least in the age range that is of interest in our study. The patients of the vasculitis group had shorter exposure to GC treatment, but the major effects of GC treatment on bone should have been manifest for a group with average GC treatment of 1.7 years. Grip strength was not measured in our subjects. The cross sectional, retrospective design did not enable collection of sufficient data on disease activity or GC dose in the past. Also, examinations at the joint were exploratory and need to be confirmed by independent studies. On the other hand, there is considerable potential for technological optimisation, specifically for the joint measurement. For example, in this pilot study no special positioning devices for the joint measurement were yet available. However, the fact that we obtained significant results, despite these limitations, is encouraging.

\section{Conclusion}

This in vivo study has shown that QUS of the phalanges is sensitive to skeletal changes due to RA. In patients with RA the two ultrasound measurements evaluated here-AD-SOS and $\mathrm{AD}-\mathrm{SoS}$ - were found to be significantly reduced compared with age matched normal reference values. This difference was already present at early stages of the disease and could be found even in the absence of erosions. AD-SoS $S_{\text {metaphysis }}$ the standard parameter of the QUS device used, correlated strongly with the cortical thickness at this site, and we conclude that it is a good measure of disease associated bone loss. The measurement of $\mathrm{AD}-\mathrm{SoS}_{\text {ioint }}$ directly at the joint provided independent information, allowing assessment of trabecular changes in RA.

QUS is a simple, portable, and inexpensive technique that is free of ionising radiation. Because of the promising results for precision and sensitivity to early changes in RA we suggest that its clinical use for monitoring skeletal changes in early RA should be evaluated in prospective studies, preferably including a direct comparison with DXA of the hand.

We thank the personnel at the Rheumaklinik Bad Bramstedt, especially chief radiologist Dr Roggensack, and the colleagues of the Department of Internal Medicine at the University of the Department of Internal Medicine at the University of recruiting patients.
1 Evans JA, Tavakoli MB. Ultrasonic attenuation and velocity in bone. Phys Med Biol 1990;35:1387-96.

2 Fuerst T, Glüer CC, Genant HK. Quantitative ultrasound. Eur J Radiol 1995;20:188-92.

3 Glüer CC, Wu CY, Jergas M, Goldstein SA, Genant HK. Three quantitative ultrasound parameters reflect bone structure. Calcif Tissue Int 1994;55:46-52.

4 Bauer DC, Glüer CC, Cauley JA, Vogt TM, Ensrud KE, Genant HK, et al. Bone ultrasound predicts fractures strongly and independently of densitometry in older women: a prospective study. Arch Intern Med 1997;157: 629-34.

5 Glüer CC, The International Quantitative Ultrasound Consensus Group. Quantitative ultrasound techniques for the assessment of osteoporosis: expert agreement on current status. J Bone Miner Res 1997;12:1280-8.

6 Glüer CC, Cummings SR, Bauer DC, Stone K, Pressman A, Mathur A, et al. Osteoporosis: association of recent fractures with quantitative US findings. Radiology 1996;199: 725-32.

7 Deodhar AA, Woolf AD. Bone mass measurement and bone metabolism in rheumatoid arthritis: a review. Br J Rheumatol 1996;35:309-22.

8 Gough AK, Lilley J, Eyre S, Holder RL, Emery P. Generalized bone loss in patients with early rheumatoid arthritis. Lancet 1994;344:23-7.

9 Buckley LM, Leib ES, Cartularo KS, Vacek PM, Cooper SM. Effects of low dose methotrexate on the bone mineral density of patients with rheumatoid arthritis. J Rheumatol 1997;24:1489-94.

10 Martin JC, Munro R, Campbell MK, Reid DM. Effects of disease and corticosteroids on appendicular bone mass in postmenopausal women with rheumatoid arthritis: comparison with axial measurements. Br J Rheumatol 1997;36: $43-9$.

11 Bywaters EGL. The early radiological signs of rheumatoid arthritis. Bull Rheum Dis 1960;11:231-4.

12 Sambrook PN, Ansell BM, Foster S, Gumpel JM, Hesp R, Reeve J. Bone turnover in early rheumatoid arthritis. 2. Longitudinal bone density studies. Ann Rheum Dis 1985; Longitudinal

13 Shimizu S, Shiozawa S, Shiozawa K, Imura S, Fujita T. Quantitative histologic studies on the pathogenesis of periarticular osteoporosis in rheumatoid arthritis. Arthritis Rheum 1985;28:25-31.

14 Hassell AB, Plant MJ, Clarke S, Fisher J, Jones PW, Saklatvala J, et al. Small joint synovitis in rheumatoid arthritis: should it be assessed separately? $\mathrm{Br} \mathrm{J}$ Rheumatol 1995;34:51-5.

15 Fries JF, Bloch DA, Sharp JT, McShane DJ, Spitz P, Bluhm $\mathrm{GB}$, et al. Assessment of radiologic progression in rheumatoid arthritis. A randomized, controlled trial. Arthritis Rheum 1986;29:1-9.

16 Sharp JT, Wolfe F, Mitchell DM, Bloch DA. The progression of erosion and joint space narrowing scores in rheumatoid arthritis during the first twenty-five years of disease. Arthritis Rheum 1991;34:660-8.

17 Pincus T, Larsen A, Brooks RH, Kaye J, Nance EP, Callahan LF. Comparison of 3 quantitative measures of hand radiographs in patients with rheumatoid arthritis: Steinbrocker stage, Kaye modified Sharp score, and Larsen score. J Rheumatol 1997;24:2106-12.

18 Reid DM, England AJ. Peripheral bone mass measurements - is there any clinical value in rheumatoid arthritis? [editorial]. Br J Rheumatol 1996;35:109-10.

19 Bouxsein ML, Michaeli DA, Plass DB, Schick DA, Melton ME. Precision and accuracy of computed digital absorptiometry for assessment of bone density of the hand. Ometry for assessment of

20 Deodhar AA, Brabyn J, Jones PW, Davis MJ, Woolf AD. Measurement of hand bone mineral content by dual energy x-ray absorptiometry: development of the method, and its application in normal volunteers and in patients with rheumatoid arthritis. Ann Rheum Dis 1994;53:685-90.

21 Peel NF, Spittlehouse AJ, Bax DE, Eastell R. Bone mineral density of the hand in rheumatoid arthritis. Arthritis Rheum 1994;37:983-91

22 Yang S-O, Hagiwara S, Engelke K, Dhillon MS, Guglielmi G, Bendavid EJ, et al. Radiographic absorptiometry for bone mineral measurement of the phalanges: precision and accuracy study. Radiology 1994;192:857-9.

23 Barnett E, Nordin BEC. The radiological diagnosis of osteoporosis: a new approach. Clin Radiol 1960;11:16674.

24 Dequeker J. Quantitative radiology: radiogrammetry of cortical bone. Br J Radiol 1976;49:912-20.

25 Saville PD, Heaney RP, Recker RR. Radiogrammetry at four bone sites in normal middle-aged women. Clin Orthop $1976 ; 307-15$

26 Dequeker J, Wielandts L, Koentges D, Nijs J. The assessment of bone loss in rheumatoid arthritis. In: Feltkamp TEW, van der Korst JK, eds. VI.S.R.A Symposium, Amsterdam. 1979;:54-63

27 Suzuki Y, Mizushima Y. Osteoporosis in rheumatoid arthritis. Osteoporos Int 1997; (suppl):S217-22.

28 Joergensen J, Andersen P, Rosholm A, Hannover Bjarnason N. Digital x-ray radiogrammetry: a new appendicular bone densitometric method with high precision. Clin Physiol 2000;20:330-5.

29 Blanckaert F, Cortet B, Coquerelle P, Flipo RM, Duquesnoy B, Delcambre B. Ultrasound velocity through the
phalanges in normal and osteoporotic patients. Calcif Tissue Int 1999;64:28-33. 
30 Guglielmi G, Cammisa M, De Serio A, Scillitani A, Chiodini I, Carnevale V, et al. Phalangeal US velocity discriminates between normal and vertebrally fractured

subjects. European Radiology 1999;9:1632-7

1 Reginster JY, Dethor M, Pirenne H, Dewe W, Albert A Reproducibility and diagnostic sensitivity of ultrasonometry of the phalanges to assess osteoporosis. Int J Gynaecol Obstet 1998;63:21-8.

32 Scavalli AS, Marini M, Spadaro A, Riccieri V, Cremona A Zoppini A. Comparison of ultrasound transmission velocity with computed metacarpal radiogrammetry and dualphoton absorptiometry. European Radiology 1996;6: photon.

33 Mele R, Masci G, Ventura V, de Aloysio D, Bicocchi M, Cadossi R. Three-year longitudinal study with quantitative ultrasound at the hand phalanx in a female population. Osteoporos Int 1997; 7:550-7.

34 Przedlacki J, Pluskiewicz W, Wieliczko M, Drozdzowska B, Matuszkiewicz-Rowinska J, Bogdanska-Straszynska B, et al. Quantitative ultrasound of phalanges and dual-energy $\mathrm{X}$-ray absorptiometry of forearm and hand in patients with X-ray absorptiometry of forearm and hand in patients with end-stage renal

35 Njeh CF, Boivin CM, Gough A, Hans D, Srivastav SK, Bulmer N, et al. Evaluation of finger ultrasound in the assessment of bone status with application of rheumatoid arthritis. Osteoporos Int 1999;9:82-90.

36 Barkmann R, Lüsse S, Stampa B, Sakata S, Heller M, Glüer CC. Assessment of the geometry of human finger phalanges using quantitative ultrasound in vivo. Osteoporosis Int 2000;11:745-55.

37 Diessel E, Alenfeld FE, Braun J, Gowin W. Ultrasound measurements of structural changes in phalanges of patients with rheumatoid arthritis. J Bone Miner Res 1997; 12(suppl 1):S388

38 Alenfeld FE, Diessel E, Brezger M, Sieper J, Felsenberg D, Braun J. Detailed analyses of periarticular osteoporosis in rheumatoid arthritis. Osteoporos Int 2000;11:400-7.

39 Cadossi R, Cane V. Pathways of transmission of ultrasound energy through the distal metaphysis of the second energy through the distal metaphysis of the second phalange

40 Glüer CC, Blake G, Lu Y, Blunt BA, Jergas M, Genant HK. Accurate assessment of precision errors: how to measure the reproducibility of bone densitometry techniques. Osteoporosis Int $1995 ; 5: 262-70$

41 Devlin J, Lilley J, Gough A, Huissoon A, Holder R, Reece R, et al. Clinical associations of dual-energy X-ray absorptiometry measurement of hand bone mass in rheumatoid arthritis. Br J Rheumatol 1996;35:1256-62.

42 Rico H, Aguado F, Revilla M, Villa LF, Martín J. Ultrasound bone velocity and metacarpal radiogrametry in hemodialyzed patients. Miner Electrolyte Metab 1994;20: 103-6.
43 Barkmann R, Heller M, Glüer CC. Methoden der in vivo-Ultraschallmesstechnik am Skelett: Grundlagen und
technische Realisierung. J Miner Stoffwechs 1999;6:22-7.

44 Genant HK, Lang TF, Engelke K, Fuerst T, Glüer CC, Majumdar S, et al. Advances in the noninvasive assessment of bone density, quality, and structure. Calcif Tissue Int 1996;59(uppl 1):S10-15.

45 Haire TJ, Langton CM. Biot theory: a review of its application to ultrasound propagation through cancellous bone. Bone 1999;24:291-5.

46 Wüster C, Albanese C, Baroncelli GPI, Federico G, Bovin $\mathrm{CM}$, Boschitsch E, et al. Phalangeal osteosonogrammetry study: age related changes, diagnostic sensitivity and discrimination power. J Bone Miner Res 2000;15:1603-14.

47 Duboeuf F, Hans D, Schott AM, Giraud S, Delmas PD, Meunier PJ. Ultrasound velocity measured at the proximal phalanges: precision and age-related changes in normal females. Rev Rhum Engl Ed 1996;6:427-34.

48 Glüer CC. Monitoring skeletal changes by radiological techniques. J Bone Miner Res 1999;14:1952-62.

49 Deodhar AA, Brabyn J, Jones PW, Davis MJ, Woolf AD. Longitudinal study of hand bone densitometry in rheumatoid arthritis. Arthritis Rheum 1995;38:1204-10.

50 Kalla AA, Meyers OL, Kotze TJ, Laubscher R. Corticosteroid therapy and bone mass-comparison of rheumatoid arthritis and systemic lupus erythematosus [see comments]. S Afr Med J 1994;84:404-9.

51 Verhoeven AC, Boers M. Limited bone loss due to corticosteroids; a systematic review of prospective studies corticosteroids; a systematic review of prospective studies
in rheumatoid arthritis and other diseases. J Rheumatol in rheumatoid arth

52 Garton MJ, Reid DM. Bone mineral density of the hip and of the anteroposterior and lateral dimensions of the spine in men with rheumatoid arthritis. Effects of low-dose corticosteroids. Arthritis Rheum 1993;36:222-8.

53 Reid DM, Kennedy NS, Smith MA, Nicoll J, Brown N, Tothill $\mathrm{P}$, et al. Bone loss in rheumatoid arthritis and primary generalized osteoarthrosis: effects of corticosteroids, suppressive antirheumatic drugs and calcium supplements. Br J Rheumatol 1986;25:253-9.

54 Felder M, Ruegsegger P. Bone loss in patients with rheumatoid arthritis-effect of steroids measured by low dose quantitative computed tomography [published erratum ppears in Rheumatol Int 1991;11:220]. Rheumatol Int 1991;11:41-4.

55 Laan RF, Buijs WC, van Erning LJ, Lemmens JA, Corstens $\mathrm{FH}$, Ruijs SH, et al. Differential effects of glucocorticoids on cortical appendicular and cortical vertebral bone mineral content. Calcif Tissue Int 1993;52:5-9.

56 Sambrook PN, Cohen ML, Eisman JA, Pocock NA, Champion GD, Yeates MG. Effects of low dose corticosteroids on bone mass in rheumatoid arthritis: a longitudinal study. Ann Rheum Dis 1989;48:535-8. 